\title{
A Continuous Casting Device with Electromagnetic Stirring for Production of SSM Feedstock Using Al-Si Alloys
}

\author{
Wendel Leme Beil ${ }^{a}$ (i), Gabriela Lujan Brollo ${ }^{a}$ (), Eugênio José Zoqui ${ }^{a}$ \\ ${ }^{a}$ Universidade de Campinas - UNICAMP, Escola de Engenharia Mecanica, Departamento de \\ Engenharia de Manufatura e Materiais, 13083-860, Campinas, SP, Brazil.
}

Received: Dezembro 22, 2020; Revised: February 19, 2021; Accepted: March 26, 2021

\begin{abstract}
This work describes the design, construction and testing of a continuous casting device coupled to an electromagnetic stirring system for the production of thixoforming feedstock using $\mathrm{Al}-\mathrm{Si}$ alloys. The following processing and construction parameters were tested: pouring temperature $\left(660-800^{\circ} \mathrm{C}\right)$, mould cavity roughness $(\mathrm{Ra}=0.17-1.06 \mu \mathrm{m})$, casting speed $(2-4 \mathrm{~mm} / \mathrm{s})$, use of a combined (primary and secondary) cooling system and the intensity and radial penetration of electromagnetic stirring $(0,1500$ and $3000 \mathrm{~W}$ stator power). The macro-appearance of the ingots and the longitudinal and radial microstructural parameters were then evaluated. The results indicate that the surface finish of the mould cavity was an important construction parameter as it had a strong influence on heat transfer and, consequently, feed speed; use of a secondary cooling system for the mould allowed greater grain refinement and microstructural homogeneity to be achieved for all the conditions tested; optimal electromagnetic stirring power was $1500 \mathrm{~W}\left(\mathrm{EMF}_{\max }=22\right.$ Gauss); this resulted in a grain size-todendritic arm spacing ratio of close to 1 , which is suitable for subsequent SSM processing.
\end{abstract}

Keywords: Continuous casting, A356 alloy, electromagnetic stirring, grain refining, thixoforming.

\section{Introduction}

Semisolid metals (SSM) processing involves mechanically forming metal alloys in the semisolid state and can be performed by cooling liquid alloy to the semisolid state ( 0.2 to 0.5 solid fraction, $\left.f_{s}\right)$ in a range of operations called rheocasting ${ }^{1,2}$ or by heating solid alloys to the semisolid condition ( 0.4 to 0.8 liquid fraction, $\mathrm{f}_{1}$ ) in a range of operations known as thixoforming ${ }^{3}$. Both processes can be superior alternatives to conventional metal forming and casting operations $\mathrm{s}^{4,5}$.

The major advantage of thixoforming over rheocasting is that the feedstock can be produced separately by conventional casting, stored and transported to the thixoforming station, where it is processed in the following steps: (a) controlled heating from the solid to the semisolid condition at a specific heating rate until the desired thixoforming temperature (and corresponding $\mathrm{f}_{1}$ ) is reached; (b) isothermal treatment at the chosen processing temperature for a specific soak time; and (c) pressing/injecting of the semisolid slurry into a mould with the preform (near-net-shape) or form (net-shape) of the final product ${ }^{6}$.

A356 and A357 hypoeutectic Al-Si alloys are amongst the most widely used commercial cast aluminium alloys in many engineering applications and are also the most widely used SSM-processed alloys ${ }^{7,8}$. During thixoforming, the Si-rich eutectic phase is completely melted and the Al-rich dendritic-like primary-phase particles remain solid and interact with each other under shear ${ }^{9}$. It is crucial for the process that the remaining solid particles in the liquid have a refined, near-spheroidal microstructure so that the semisolid

"Corresponding author: zoqui@fem.unicamp.br slurry has a thixotropic rheology, as this is responsible for the advantageous smooth, laminar mould-filling characteristic of SSM processing ${ }^{10-13}$. The microstructure of the raw metal, amongst other factors (such as heating rate, processing temperature, soak time and shear rate during thixoforming), plays a crucial role in determining the microstructure and, consequently, rheology of the semisolid slurry.

The use of electromagnetic stirring (EMS) in casting results in an optimized feedstock microstructure for SSMprocessing applications ${ }^{14-18}$. Magnetic stirrers use Lorentz forces to produce convection in the liquid near the solidification front, which in turn generates shear stresses that cut away newly formed dendrites. The debris is then transported by convection into the liquid farther from the solid/liquid interface to higher-temperature regions in the molten metal. Part of the debris melts and disappears while the surviving broken dendrites act as new nucleation sites. The result is powerful grain refinement and a non-dendritic microstructure in the final casting. Furthermore, EMS optimizes chemical homogenization of the ingot, reduces defects such as porosity and segregation and contributes to the refining of $\mathrm{Si}$ and $\mathrm{Fe}$ platelets from the interdendritic eutectic aggregate ${ }^{16,19,20}$.

The Semisolid Processing Group in the Faculty of Mechanical Engineering at the University of Campinas (UNICAMP) has undertaken several research efforts to produce feedstock suitable for use in thixoforming. These include investigation of processing routes using chemical grain refining and electromagnetic, mechanical and ultrasonic stirring with static and semicontinuous casting ${ }^{21-29}$

The present study, which describes the design and construction of a continuous-casting device with EMS for the 
efficient production of $\mathrm{Al}$ alloys with a refined microstructure, represents a new attempt to expand production routes for raw materials for thixoforming. As the volume of SSM alloys produced worldwide is $l o w^{30}$, there is little interest among large foundries in exploring novel production routes. The device developed here overcomes this problem by allowing small foundries to produce raw material for this growing market. Furthermore, the proposed device could easily be adapted to produce larger-diameter ingots than the $30 \mathrm{~mm}$-diameter A356 ingots produced in the study. Although rheocasting is more widely used than thixoforming, homogeneous, controlled heating of an ingot for thixoforming is more easily achieved in an industrial context than homogeneous, controlled cooling of a liquid for rheocasting.

\section{Experimental Procedure}

The chemical composition of the A356 alloy studied was determined with an Anacon BILL optical emission spectrometer (OES), shown in Table 1, complies with the composition specified in ASTM standard B179-18 $18^{31}$ as well as in the literature ${ }^{32}$.

The microstructures were observed in bright field (BF) and with polarized light (PL) in an optical microscope (MO) Leica DM ILM. For PL, samples were etched electrolytically in $1.8 \% \mathrm{HBF} 4$ at $0.5 \mathrm{~A}$ and $30 \mathrm{~V}$ for $3.5 \mathrm{~min}$ under stirring. In PL grains with the same crystal orientation had similar colourings. Grain size (GS) measurements were performed by applying the Heyn intercept method ${ }^{33}$ on the microscopic images: each grain crossing the axes was considered a continuous portion of the material when it had the same colour $^{33,34}$. Counts were performed in five different fields of each micrograph, and five images of different sections were used for each sample, giving a total of twenty-five counts per region of the ingot. Bright field micrographs were used to determine dendrite arm spacing (DAS), by the Heyn intercept method ${ }^{33}$.

Micrographs of the as-received cast alloy are shown in Figure 1. These highlight (a) the grains formed by dendrites of the Al-rich primary phase ( $\mathrm{GS} \sim 3 \mathrm{~mm}$ ) and (b) the eutectic phase, composed mainly of $\mathrm{Al}_{\mathrm{FCC}}$ intercalated with lamellar $\mathrm{Si}$. Both micrographs show that grain size in as-cast alloys can adversely affect the thixoforming process. Coarse grains in the posterior thixoforming process impairs the smooth flow of the slurry. It is necessary a starting material with refined microstructure ${ }^{4,5}$.

DAS is an important feature of the alloy as the raw material produced will be thixoformed subsequently. For SSM processing purposes, the ratio GS/DAS that indicates the degree of connection between independent $\alpha$-phase units ${ }^{35}$, i.e., the complexity of the three-dimensional dendritic skeleton. When partially melted during thixoforming, the raw material will suffer the effects of coarsening mechanisms (Ostwald ripening and coalescence). A large number of secondary and tertiary dendrite arms will be separated from the primary dendritic body and turn into independent globules surrounded by liquid. The lesser the degree of interconnection, i.e., GS/DAS $\rightarrow 1$, the smaller and rounder the solid globules during thixoforming and the better will be the rheological behaviour of the semisolid slurry, allowing smooth mould filing. A complete explanation of the relationship between grain and globule can be found in an earlier work ${ }^{35}$.

The microstructure of the ingots produced by the device developed here was analyzed in samples taken from different regions of the ingots, as shown in Figure 2. Longitudinal section 1 (also shown in detail A) is the end of the ingot in

Table 1. Chemical composition of the A356 alloy as measured by OES and the expected range (min-max) of wt. \% values for each element specified at ASTM B179-18 ${ }^{31}$.

\begin{tabular}{rcccccccc}
\hline \multirow{2}{*}{$\mathrm{A} 356$} & \multicolumn{9}{c}{ Chemical Composition (wt.\%) } \\
\cline { 2 - 9 } & $\mathrm{Si}$ & $\mathrm{Mg}$ & $\mathrm{Fe}$ & $\mathrm{Cu}$ & $\mathrm{Mn}$ & $\mathrm{Ti}$ & $\mathrm{Res}^{1}$ & $\mathrm{Al}$ \\
\hline B179-18 & $6.50-7.50$ & $0.25-0.45$ & $\leq 0.20$ & $\leq 0.20$ & $\leq 0.10$ & $\leq 0.20$ & $\leq 0.20$ & $\mathrm{Bal}^{2}{ }^{2}$ \\
\hline Sample $^{3}$ & $6.76 \pm 0.22$ & $0.38 \pm 0.02$ & 0.16 & 0.09 & 0.01 & 0.005 & 0.10 & Bal. $^{2}$ \\
\hline
\end{tabular}

${ }^{1}$ Sum of residual elements. ${ }^{2}$ Balance. ${ }^{3}$ When not specified, standard deviation is $<0.05$.
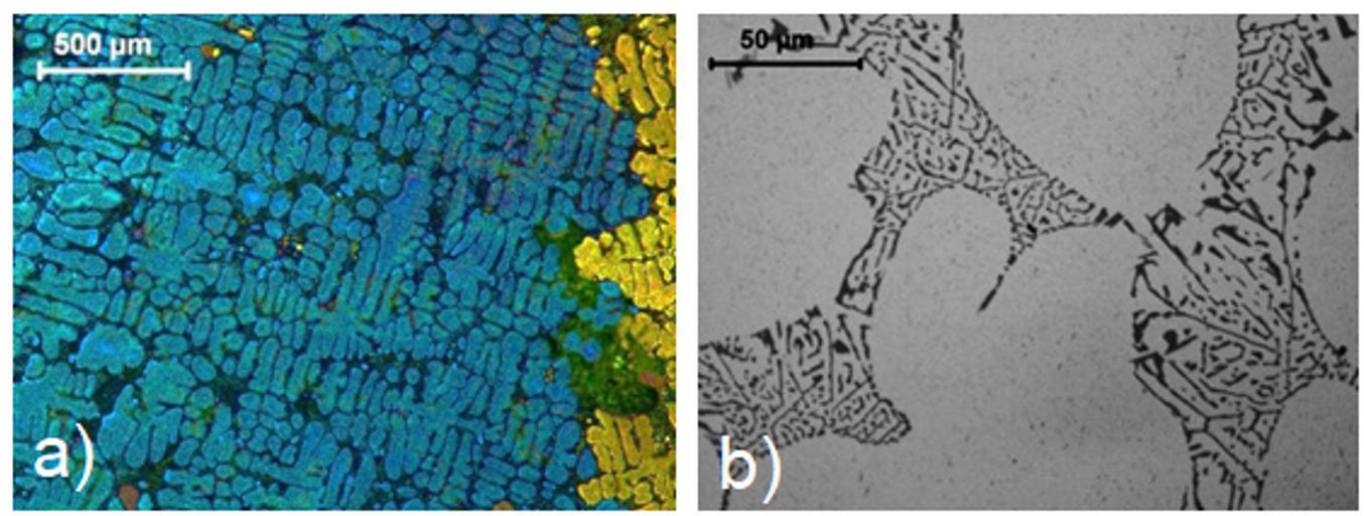

Figure 1. Optical micrographs of the as-received A356 alloy. (a) Polarized-light image micrograph highlighting the Al-rich dendritic grains; (b) BF image highlighting the Si-rich eutectic interdendritic (dark needles) and $\mathrm{Al}_{\mathrm{FCC}}$ phase (gray surface). 


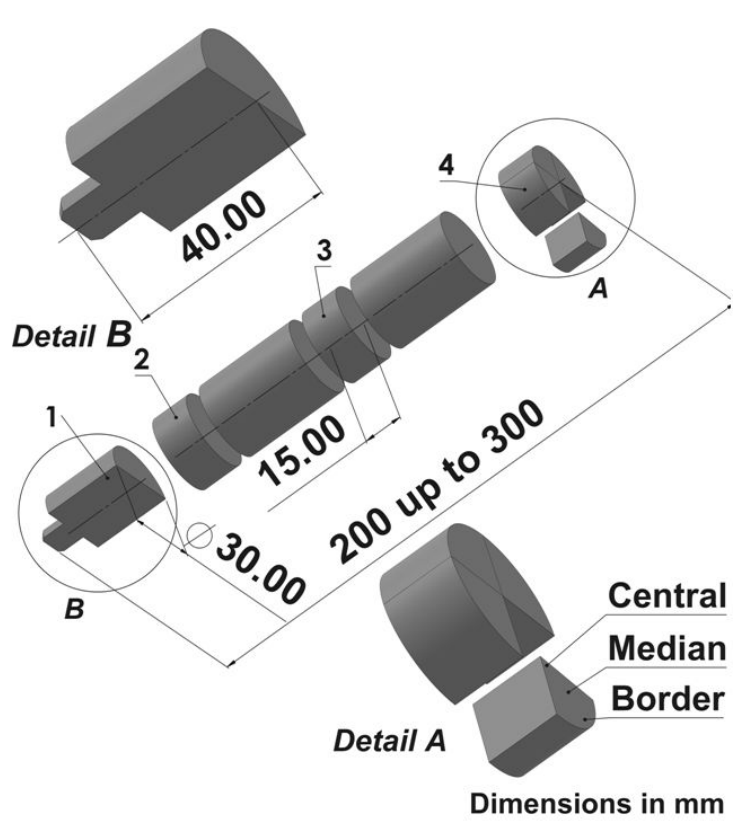

Figure 2. Schematic diagram showing the different regions of the ingot. (1) (Detail A) bottom section of the ingot in contact with the extractor device, where there is a transient heat-transfer regime; (2) proximal, (3) medial and (4) distal sections, where there is a steady-state heat transfer regime; (detail B) radial locations (centre, middle and edge) analyzed for regions 1 to 4 .

direct contact with the extractor device (the dummy bar). Along the length of this section there is a transient heattransfer regime because heat is transferred simultaneously in two directions: longitudinally (between the flat bottom of the ingot and the extractor) and radially (between the surface of the ingot and the internal mould wall). This transient regime results in a gradual change in the microstructure, and the region where this regime is present must therefore be discarded from the final ingot. Sections 2, 3 and 4 correspond to the proximal, medial and distal regions of the ingot with respect to the extractor, respectively. In these regions, steadystate heat transfer is observed, i.e., only radial heat transfer occurs along the entire length, resulting in a homogeneous microstructure. These regions therefore represent the useful length of the ingot. Detail B shows three locations along a radial section (centre, middle and edge) analyzed for each of the regions 1 to 4 described above.

The surface finish of the mould cavity was evaluated based on three different average roughness values: $\mathrm{Ra}=1.06$, 0.18 and $0.06 \mu \mathrm{m}$. Roughness profiles were generated for the entire cavity length with a MarSurf portable roughness measuring instrument (Mahr, Göttingen, Germany). A $2.5 \mathrm{~mm}$ cut-off was adopted and maintained for all the measurements. Each measurement was performed at three different positions separated by $120^{\circ}$ along the cavity circumference. The effectiveness of EMS of the molten metal was evaluated for three different levels of power applied to the electromagnetic field (EMF) generator: 0, 1500 and $3000 \mathrm{~W}$. The coil system used is nothing more than the stator of a conventional electric motor of $6 \mathrm{~kW}(8 \mathrm{hp})$, controlled by a three-phase voltage source, rectified in direct current, with the capacity to generate up to $8 \mathrm{~kW} 220 \mathrm{~V} 20 \mathrm{~A}$. EMF profiles from the edge to the centre of the mould and along the entire length of the mould (measured every $10 \mathrm{~mm}$ ) were generated with a Lakeshore 410 gaussmeter that allows measurements in the $0.1 \mathrm{G}$-to- $20 \mathrm{kG}$ range.

A general limitation of the system was synchronization between pouring and casting speeds and the rate at which heat was extracted from the system. Metal feeding was performed manually and vertically with the aid of gravity (conventional pouring), a procedure that can potentially give rise to biofilms in the cast ingots, the main source of several known casting defects ${ }^{36-39}$. Synchronization of feeding and casting is strongly dependent on the melted fluidity as it enters the mould and is essential to guarantee a constant volume (flow) of metal being cast. Fluidity, in turn, depends upon many factors related to the molten metal, mould, metal/mould interface etc. ${ }^{40,41}$, making synchronization a challenge when manual pouring is used. Furthermore, heat transfer between ingot, mould and environment should be sufficient to prevent excessive grain growth and allow a sufficiently thick, solid shell to form and the mushy zone (where solid and liquid coexist in the solidifying ingot) to develop a substantial coherent volume, i.e., a solid matrix substantial enough to bear the extraction $\operatorname{load}^{42-44}$. Application of a conductive coating (e.g., graphite) or use of a highly conductive alloy as mould material could help to accelerate solidification ${ }^{45,46}$.

The details of the entire construction system, as well as the determination of the operating conditions of the equipment are presented extensively in Appendix A - Design and construction of the continuous casting device, as well as in Appendix B - Choice of processing and construction parameters as a supplementary material of this work. This is important information, which also includes the failures and their reasons, to assist researchers who wish to replicate the system as well as for small companies that wish to build a similar system. The chosen operating condition, which obviously generated the best ingots, implied a pouring temperature of $800{ }^{\circ} \mathrm{C}$, low roughness in the mould cavity, $0.06 \mu \mathrm{m}$, casting speed of $3 \mathrm{~mm} / \mathrm{s}$ and useful length of the mould, i.e. , the depth measured between the liquid surface and the solidified part between 15 and $20 \mathrm{~mm}$. The route 4 chosen (Appendix B) was repeated five times successfully.

\section{Results and Discussion}

\subsection{Determining the position at which steady state is reached}

Figure 3 shows the microstructure in the middle of the radius of longitudinal section 1 of the ingot (see scheme in Figure 2) at increasing distances from the extractor. The images show how the microstructure changed from the point at which the ingot first began to form, i.e., where it was in contact with the extractor, until the point at which a steady state was reached and allow the length of ingot that should be discarded to be determined. The steady state was considered to have been reached when the microstructure became homogeneous. That part of the ingot between the point at which this steady-state microstructure was observed and the extractor, i.e., where the microstructure was in 

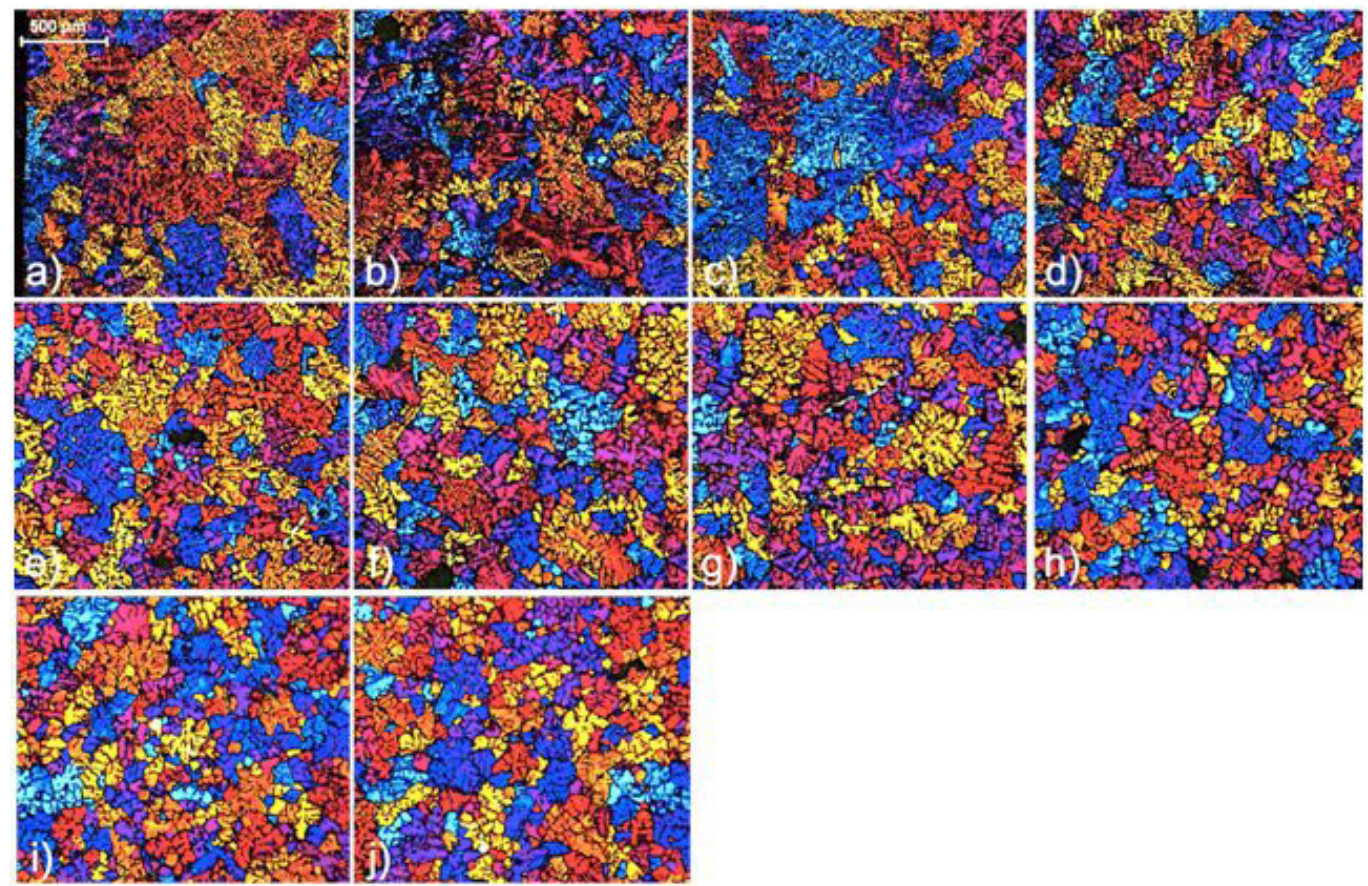

Figure 3. PL microstructure of longitudinal section 1 of the ingot at increasing distances from the extractor: (a) 2.5, (b) 5.0 , (c) 7.5 , (d) 10.0, (e) 12.5, (f) 15.0, (g) 17.5, (h) 20.0, (i) 22.5 and (j) $25 \mathrm{~mm}$.

transition, was then discarded. The images in Figure 3 show the microstructure at increasing distances $(2.5 \mathrm{~mm}$ increments) from the extractor: (a) $2.5 \mathrm{~mm}$, (b) $5.0 \mathrm{~mm}$, (c) $7.5 \mathrm{~mm}$, (d) $10.0 \mathrm{~mm}$, (e) $12.5 \mathrm{~mm}$, (f) $15.0 \mathrm{~mm}$, (g) $17.5 \mathrm{~mm}$, (h) $20.0 \mathrm{~mm}$, (i) $22.5 \mathrm{~mm}$ and (j) $25 \mathrm{~mm}$.

Near the extractor (Figure 3a), solidification resulted in strongly oriented grain growth in the form of elongated dendrites as heat transfer in this region took place not only in the radial direction (i.e., at the circumference of the mould along its length) but also in the longitudinal direction (i.e., at the flat surface at the bottom of the ingot). This geometrical asymmetry had a major impact on the microstructure at distances of up to $7.5 \mathrm{~mm}$ from the extractor (a-c) and a minor impact at distances of 7.5 to $17.5 \mathrm{~mm}(\mathrm{~d}-\mathrm{g})$. From 17.5 to $25 \mathrm{~mm}(\mathrm{~h}-\mathrm{j})$, grains were more refined and equiaxed, indicating more uniform heat transfer dictated entirely by the interaction between the ingot and the radial surface of the mould (steady state). As a conservative measurement, $30 \mathrm{~mm}$ of each ingot was discarded from the total length of $200-300 \mathrm{~mm}$, and the remainder was considered the useful length of the ingot. If the maximum capacity of the system were used, ingots around $2000 \mathrm{~mm}$ long could be produced.

\subsection{Radial depth of penetration of the EMF}

Once the useful length of the ingots had been determined, the next step was to determine the penetration depth of the EMF in a radial direction from the edge to the centre of the ingots in region 1 immediately after the steady state had been achieved, i.e., more than $30 \mathrm{~mm}$ from the extractor end of the ingot. Figure 4 shows the change in the microstructure at three positions along a radial cross section (edge - a,d; middle $-\mathrm{b}, \mathrm{e}$; centre $-\mathrm{c}, \mathrm{f}$ ) of region 1 of an ingot (see Figure 2 detail B) cast by route 4 (Appendix B) with primary cooling $(\mathrm{PC}-\mathrm{a}, \mathrm{b}, \mathrm{c})$ and primary + secondary cooling $(\mathrm{PSC}-\mathrm{d}, \mathrm{e}, \mathrm{f})$ without EMS (power $=0 \mathrm{~W}$ ).

For both cooling conditions ( $\mathrm{PC}$ and PSC), the absence of EMS led to a transition in the microstructure from the edge to the centre (left to right) because of the gradual reduction in heat transfer from the ingot to the mould: contact with the surface of the mould resulted in significant grain refinement at the edge of the ingot, and as heat transfer became progressively slower, a corresponding progressive coarsening in the middle and central regions was observed. As expected, the use of PSC led to better refinement at all points along the ingot radius than $\mathrm{PC}$ alone.

When EMS is used, the change in microstructure along the radial section of the ingot is caused by a combination of the change in heat transfer (as discussed above) and the intensity of the EMF. Figure 5 shows the change in EMF along the mould at the centre $(0 \mathrm{~mm} \mathrm{R})$ and edge $(15 \mathrm{~mm} \mathrm{R})$ of the cavity for power levels of 1500 and $3000 \mathrm{~W}$. Note that it should be understood that liquid metal can alters these measurements completely.

It should be remembered that the ingot begins to form (solidify) at $45 \mathrm{~mm}$, after the aluminium oxide coating, but increase the solidification when it is 70 to $110 \mathrm{~mm}$ long as it is pulled by the extractor and casting progresses. The $\mathrm{K}$-type thermocouple is inserted approximately $85 \mathrm{~mm}$ from the top of the mould. The total length of the mould is $135 \mathrm{~mm}$, and it is only in the last $40 \mathrm{~mm}$ (corresponding to approximately 


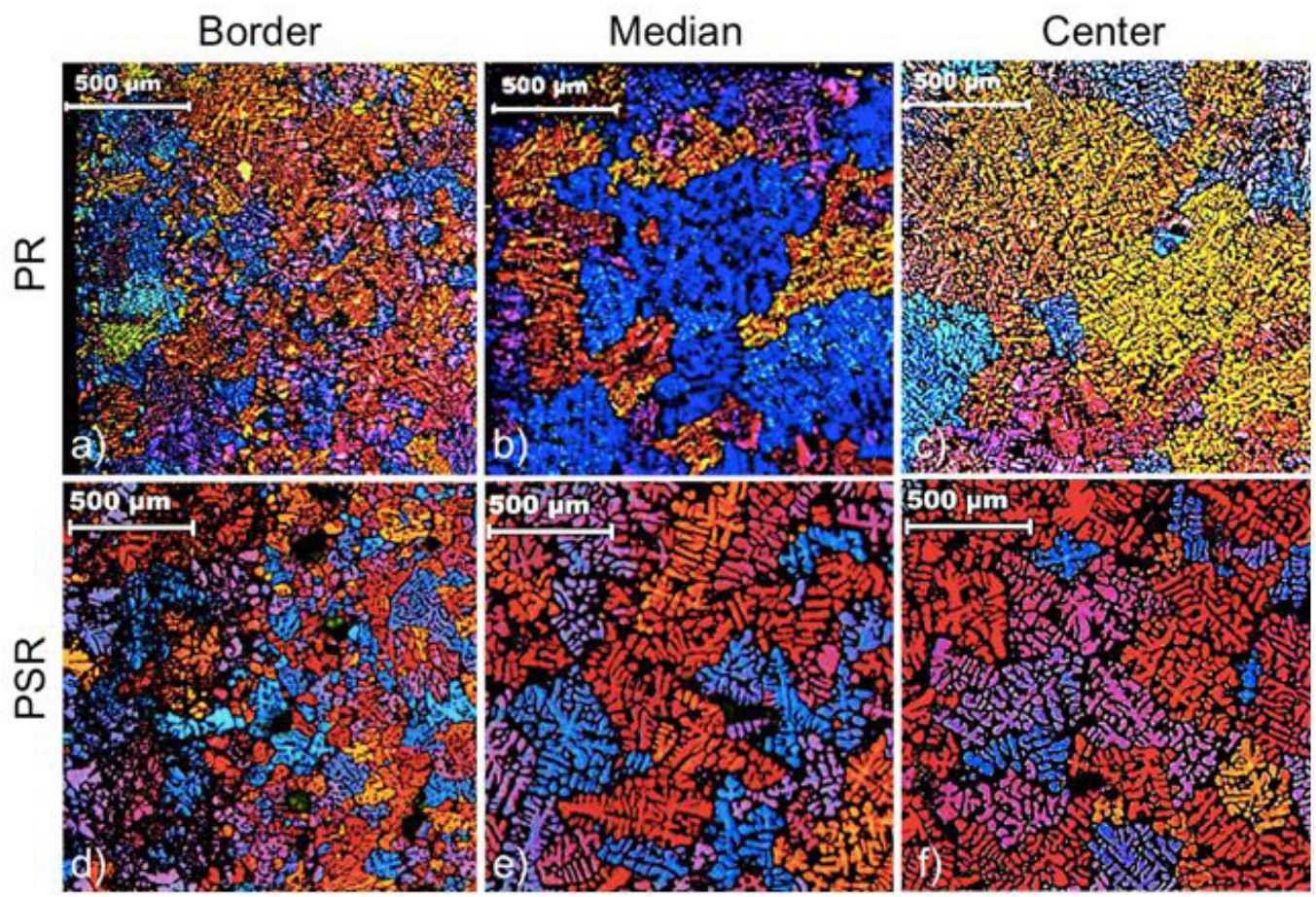

Figure 4. PL microstructure at three locations along a radial cross section of region 1 of an ingot (edge - a, d; middle - b, e; centre - c, f) cast by route 4 without EMS ( $0 \mathrm{~W})(\mathrm{a}-\mathrm{f})$ and with PC (a-c) and PSC (d-f).

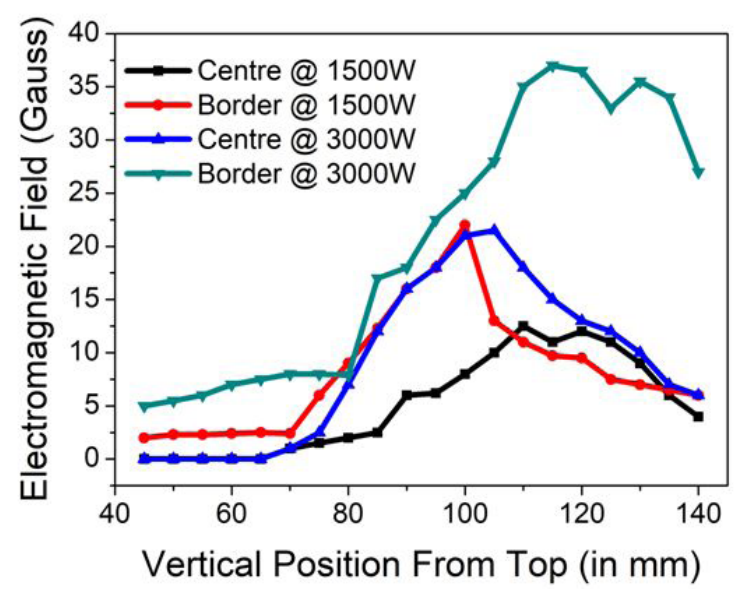

Figure 5. Electromagnetic field as a function of distance from the top of the mould measured at the centre $(0 \mathrm{~mm} \mathrm{R})$ and edge $(15 \mathrm{~mm}$ $\mathrm{R})$ of the cavity for power levels of 1500 and $3000 \mathrm{~W}$.

$12 \mathrm{~s}$ for a feed speed of $3 \mathrm{~mm} / \mathrm{s}$ ) that the ingot solidifies sufficiently to come fully into contact with the mould. The EMF exerts an influence from $70 \mathrm{~mm}$ to $135 \mathrm{~mm}$, i.e., during the final stages of solidification, which occurs after the final contact between the ingot and mould, when the centre of the ingot is still liquid. From 135 to $200 \mathrm{~mm}$ the EMF profile in
Figure 5 is influenced by the SC system, which completes the solidification under stirring.

Between 100 and $135 \mathrm{~mm}$ the ingot is cooled by the PC system inside the mould, and at approximately $140 \mathrm{~mm}$ it is cooled by the spray from the SC system. Although the ingot is still subjected to the EMF after it has passed through both cooling systems, i.e., when it is longer than $140 \mathrm{~mm}$, it can be considered completely solidified and the EMF therefore has no effect on grain refinement.

Along that part of the mould where the EMF exerts an influence ( 80 to $140 \mathrm{~mm}$ ), the field intensity at $3000 \mathrm{~W}$ is always higher than at $1500 \mathrm{~W}$ at both the centre and edge of the ingot. At the beginning of solidification (circa $80 \mathrm{~mm}$ ), the ratio $\mathrm{EMF}_{3 \mathrm{~kW}} / \mathrm{EMF}_{1.5 \mathrm{~kW}}=0.9$ at the edge and 3.5 at the centre of the ingot; at the end of solidification $(140 \mathrm{~mm}$ length) the corresponding values were 4.5 and 1.5. For $3000 \mathrm{~W}$, maximum EMF was at the end of solidification for the edge $\left(\mathrm{EMF}_{\max }=38 \mathrm{G}\right)$, and although this same trend was observed at the centre of the ingot for $1500 \mathrm{~W}$, the maximum EMF at the edge for this lower power level was reached earlier, at $100 \mathrm{~mm}\left(\mathrm{EMF}_{\max }=22 \mathrm{G}\right)$.

The radial depth of penetration of the EMF can be evaluated using the ratio of the EMF at the edge of the ingot to the EMF at the centre. The closer this parameter $\left(\mathrm{EMF}_{\mathrm{EDGE}} /\right.$ $\left.\mathrm{EMF}_{\text {CENTRE }}\right)$ is to 1, the greater the penetration. Poor depth of penetration $\left(\mathrm{EMF}_{\mathrm{EDGE}} / \mathrm{EMF}_{\mathrm{CENTRE}}>>1\right)$ can lead to a larger variation in microstructure in the radial direction. At a length of $100 \mathrm{~mm}, \mathrm{EMF}_{\mathrm{EDGE}} / \mathrm{EMF}_{\mathrm{CENTRE}}=2.8$ for $1500 \mathrm{~W}$, and this 
is reduced to 1.2 when the power is increased to $3000 \mathrm{~W}$. At $140 \mathrm{~mm}$, this trend is inverted: for $1500 \mathrm{~W}, \mathrm{EMF}_{\mathrm{EDGE}} /$ $\mathrm{EMF}_{\mathrm{CENTRE}}=1.5$ and for $3000 \mathrm{~W} \mathrm{EMF}_{\mathrm{EDGE}} / \mathrm{EMF}_{\mathrm{CENTRE}}=4.5$. Hence, for $1500 \mathrm{~W}$ the EMF penetration depth is greater in that part of the mould where most of the solidification occurs. When the power is increased to $3000 \mathrm{~W}$, penetration depth decreases as solidification progresses.

Figure 6 and 7 show exactly the same features as in Figure 4, this time for EMS with power levels of 1500 and $3000 \mathrm{~W}$, respectively. At $1500 \mathrm{~W}$, EMS produced significant grain refinement compared with casting without stirring, and the use of two cooling systems rather than one also improved the grain refinement. Furthermore, the microstructure is homogeneous in the radial direction, indicating that the EMF produced with a power level of $1500 \mathrm{~W}$ was effective in fragmenting the dendritic microstructure and transporting through the liquid the resulting broken particles, which served as nuclei for new grains.

For EMS with a power level of $3000 \mathrm{~W}$, grain refinement was very limited. A possible explanation for this is that the extensive stirring produced by the higher power displaced the solute from the bases of dendritic arms, avoiding the necking mechanism responsible for fragmentation. Furthermore, the mechanical bending of dendritic arms caused by intensive stirring may have caused physical contact between neighbouring dendrites, favouring coalescence instead of fragmentation.

Also, for $3000 \mathrm{~W}$ there is a visible change in the microstructure in the radial direction, indicating poorer penetration depth. This effect is expected since the shearing forces generated by the EMF are stronger at the edge and decrease progressively towards the centre of the ingot, a phenomenon known as the skin effect. This undesirable effect was not observed for $1500 \mathrm{~W}$, probably because of the lower AC frequency used for this power level. Although the lower AC frequency results in the EMF having less total energy (see Figure 5), it helps to improve the depth of penetration of the EMS in the melt, as shown by the relationship $\delta=\sqrt{\rho / \pi \mu f}$, where $\delta$ is the skin depth, $\rho$ and $\mu$ are the resistivity and permeability of the molten metal and $f$ is the AC frequency ${ }^{17}$. Use of PSC at $3000 \mathrm{~W}$ resulted in slightly better refinement than when only PC was used.

\subsection{Stability of the casting process}

After analysis of the effect of the EMF, the stability of the casting process was evaluated based on the microstructural homogeneity along the useful length of the ingot. Although the device described here can produce ingots up to 2000 $\mathrm{mm}$ long, for the purposes of assessing the stability of the casting process only $200 \mathrm{~mm}$-long ingots were cast. Figures 8 and 9 show polarized colour micrographs taken at the middle of a radial cross section in distal (a, d, g), medial (b, e, h) and proximal (c, f, i) sections of an ingot (see Figure 2) cast by route 4 (Appendix B) with PC (Figure 8) and PSC (Figure 9) and without EMS (a, b, c) and with EMS (1500 W: d, e, f; $3000 \mathrm{~W}: \mathrm{g}, \mathrm{h}, \mathrm{i}$ ) in which grain size (GS) can be characterized. Figure 10 shows the same information but in conventional B\&W images,

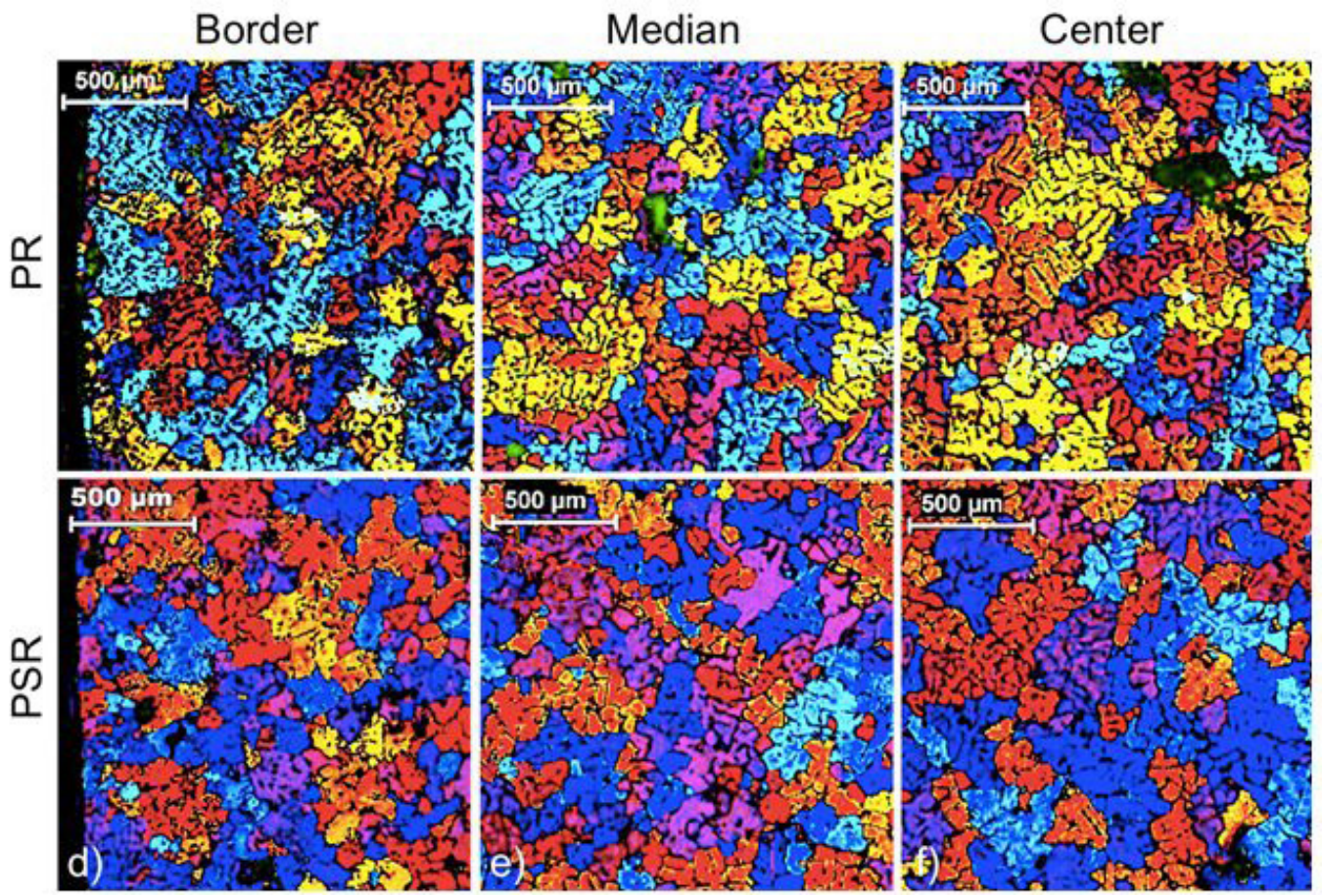

Figure 6. PL microstructure at three locations along a radial cross section of region 1 of an ingot (edge - a, d; middle - b, e; centre - c, f) cast by route 4 with EMS (1500 W) (a-f) and PC (a-c) and PSC (d-f). 
which allow DAS to be determined. As there was very little variation in the conventional $\mathrm{B} \& \mathrm{~W}$ micrographs along the ingot, only those corresponding to the medial position are shown. Table 2 shows the values of the microstructural parameters (average \pm standard deviation) for all the processing conditions in Figures 8, 9 and 10 and allows the small differences in these values to be more readily observed.

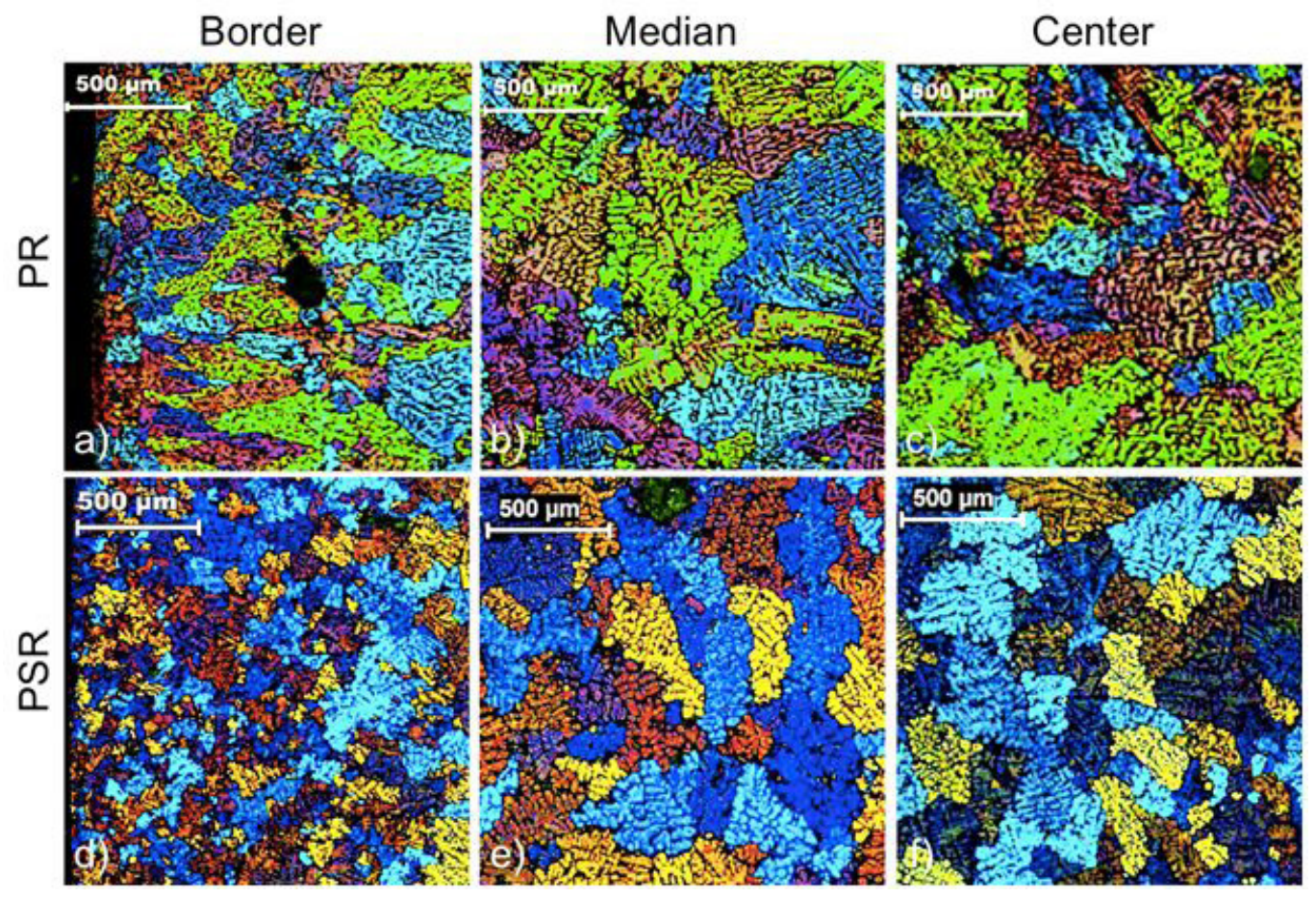

Figure 7. PL microstructure at three locations along a radial cross section of region 1 of an ingot (edge - a, d; middle - b, e; centre - c, f) cast by route 4 with EMS (3000 W) (a-f) and PC (a-c) and PSC (d-f).

Table 2. Values of microstructural parameters (average \pm standard deviation) for the distal, medial and proximal regions of an ingot cast by route 4 with PC and PSC and without EMS (0 W) and with EMS (1500 and $3000 \mathrm{~W})$. All values in $\mu \mathrm{m}$.

\begin{tabular}{|c|c|c|c|c|c|}
\hline \multirow{2}{*}{ Cooling System } & \multirow{2}{*}{ Parameter } & \multirow{2}{*}{ Stirring (W) } & \multicolumn{3}{|c|}{ Region } \\
\hline & & & Proximal & Medial & Distal \\
\hline \multirow{9}{*}{$\mathrm{PC}$} & \multirow{3}{*}{$\mathrm{GS}(\mu \mathrm{m})$} & 0 & $495 \pm 113$ & $482 \pm 126$ & $530 \pm 114$ \\
\hline & & 1500 & $176 \pm 27$ & $154 \pm 35$ & $172 \pm 33$ \\
\hline & & 3000 & $549 \pm 118$ & $480 \pm 124$ & $526 \pm 108$ \\
\hline & \multirow{3}{*}{$\operatorname{DAS}(\mu \mathrm{m})$} & 0 & $48 \pm 10$ & $47 \pm 8$ & $50 \pm 13$ \\
\hline & & 1500 & $45 \pm 7$ & $47 \pm 11$ & $46 \pm 5$ \\
\hline & & 3000 & $78 \pm 8$ & $82 \pm 7$ & $80 \pm 9$ \\
\hline & \multirow{3}{*}{ GS/DAS } & 0 & $10.8 \pm 2.9$ & $10.2 \pm 3.1$ & $10.3 \pm 2.9$ \\
\hline & & 1500 & $3.9 \pm 0.8$ & $3.4 \pm 0.8$ & $3.7 \pm 0.8$ \\
\hline & & 3000 & $7.0 \pm 2.4$ & $5.8 \pm 2.4$ & $6.6 \pm 2.3$ \\
\hline \multirow{9}{*}{ PSC } & \multirow{3}{*}{$\mathrm{GS}(\mu \mathrm{m})$} & 0 & $335 \pm 74$ & $353 \pm 59$ & $293 \pm 52$ \\
\hline & & 1500 & $181 \pm 13$ & $178 \pm 17$ & $180 \pm 15$ \\
\hline & & 3000 & $237 \pm 16$ & $242 \pm 18$ & $235 \pm 14$ \\
\hline & \multirow{3}{*}{$\mathrm{DAS}(\mu \mathrm{m})$} & 0 & $56 \pm 12$ & $52 \pm 15$ & $55 \pm 12$ \\
\hline & & 1500 & $111 \pm 7$ & $126 \pm 15$ & $125 \pm 14$ \\
\hline & & 3000 & $84 \pm 7$ & $91 \pm 15$ & $88 \pm 14$ \\
\hline & \multirow{3}{*}{ GS/DAS } & 0 & $5.9 \pm 1.1$ & $6.1 \pm 1.1$ & $5.3 \pm 1.1$ \\
\hline & & 1500 & $1.6 \pm 0.2$ & $1.4 \pm 0.2$ & $1.5 \pm 0.2$ \\
\hline & & 3000 & $2.8 \pm 0.2$ & $2.7 \pm 0.3$ & $2.7 \pm 0.4$ \\
\hline
\end{tabular}




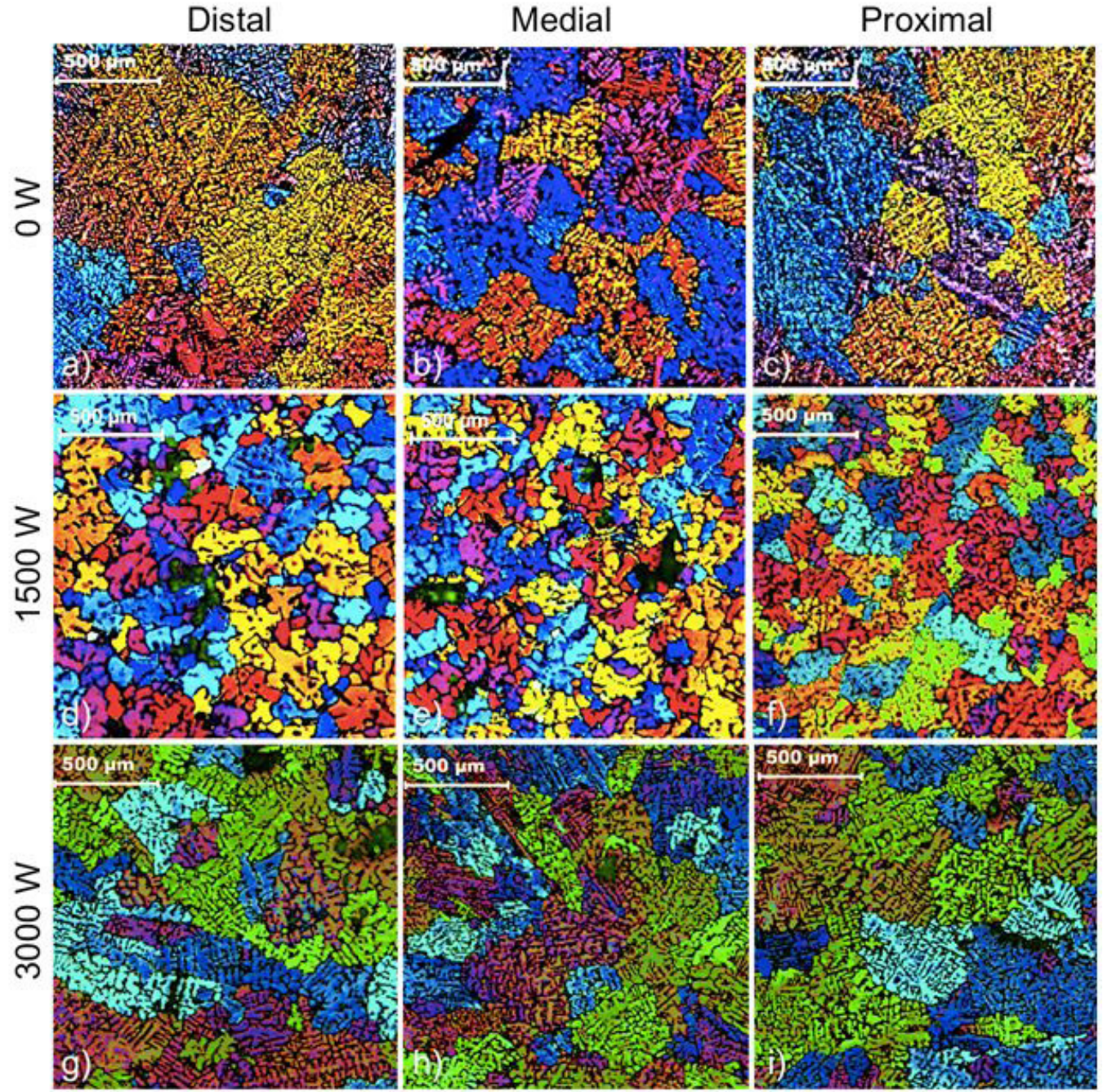

Figure 8. PL microstructure of distal (a, d, g), medial (b, e, h) and proximal (c, f, i) regions of an ingot cast by route 4 with PC and without EMS (a, b, c) and with PC and with EMS (1500 W: d, e, f; $3000 \mathrm{~W}: \mathrm{g}, \mathrm{h}, \mathrm{i})$.

Ingots cooled with only PC had refined, homogeneous grains along their length when stirring at $1500 \mathrm{~W}$ was used (Figure 8d, e, f and Figure 10b). However, when no stirring $(0 \mathrm{~W})$ or stirring at $3000 \mathrm{~W}$ was used, GS values were larger and, more importantly, had a large standard deviation, leading to the spread in the data seen in the graph. This is an indication of the simultaneous presence of large and fine grains spread along the same microstructure, which may be caused by excessive growth of a few grains oriented preferentially amongst others, probably respecting the intrinsic preferential directions of the FCC crystal lattice. The similar values of GS without stirring and with stirring at $3000 \mathrm{~W}$ also indicate the poor grain refinement achieved under the latter condition, as explained in Section 3.2.

A more effective cooling system combining PC and SC (Figure 9 and Figure 10d, e, f) resulted in smaller differences in the values of GS between the three conditions tested. For stirring at $3000 \mathrm{~W}$, not only was a reduction in GS observed but also a substantial reduction in the spread of the data (standard deviation). Under stirring at $1500 \mathrm{~W}$, GS was practically unaltered by the use of $\mathrm{SC}$, indicating that the grain refinement achieved with EMS was so effective that further refinement by cooling had no effect.

As mentioned before, Figure 10 shows B\&W micrographs of the medial region of ingots cast by route 4 with and without EMS (0 W: a,d; $1500 \mathrm{~W}$ : b, e; 3000 W: c, f) and with PC (top) and PSC (bottom). The DAS can be better visualized in these images than in the colour micrographs and can be compared with the results shown in Figure 8 and 9.

The DAS without EMS ( $0 \mathrm{~W})$ is visibly similar for both cooling conditions (Figure 10a and d) and always smaller than when stirring was used. Conventional dendrite growth is clearly recognizable. However, when an electromagnetic field is applied, stirring causes dendrite 


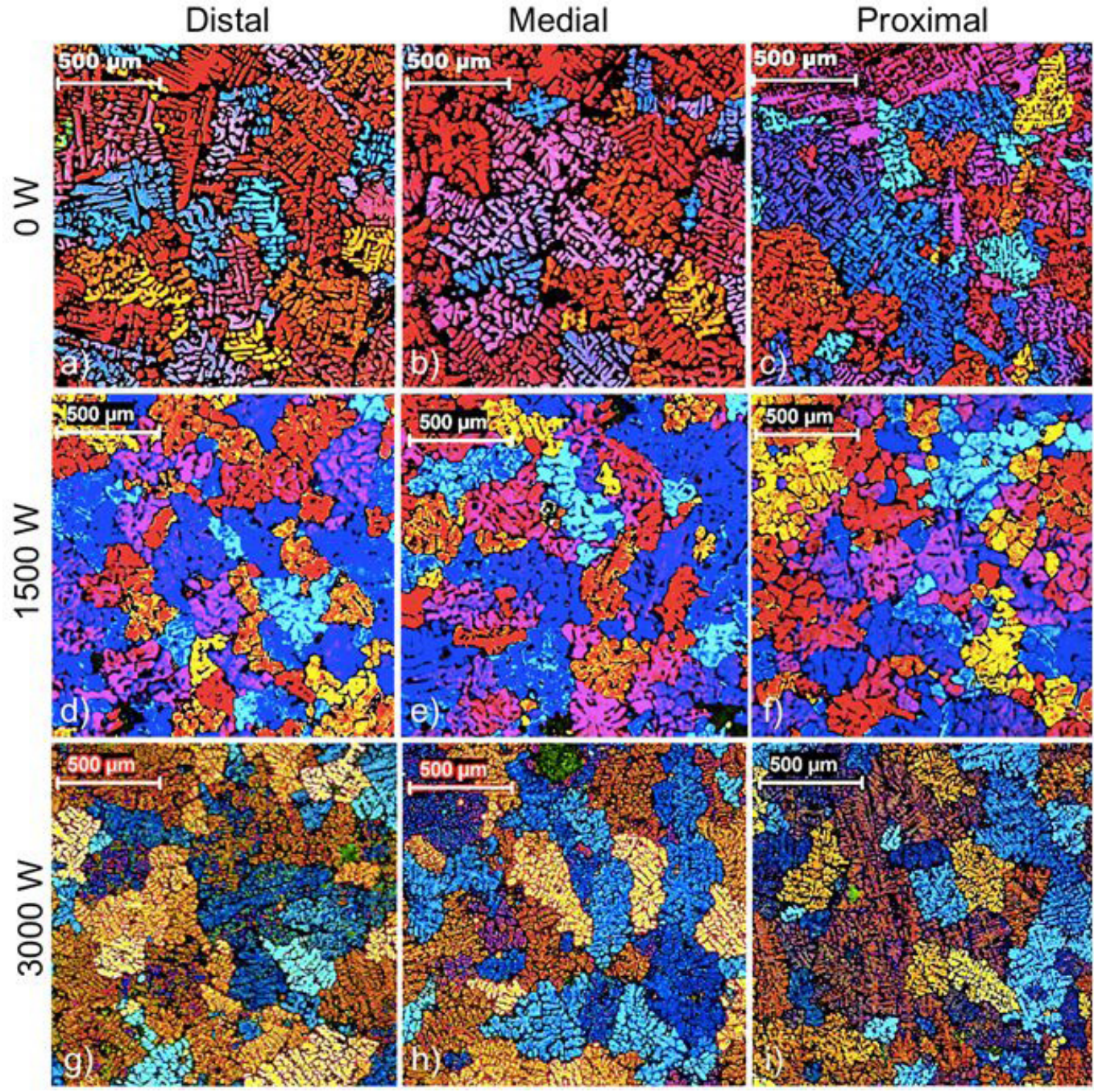

Figure 9. PL microstructure of distal (a, d, g), medial (b, e, h) and proximal (c, f, i) regions of an ingot cast by route 4 with PSC and without EMS (a, b, c) and with PSC and with EMS (1500 W: d, e, f; $3000 \mathrm{~W}: \mathrm{g}, \mathrm{h}, \mathrm{i})$.

arms that are forming to bend and detach and the solute in the liquid between dendrite arms beside each other to be removed, reducing the separation between dendrites and favouring dendrite formation. For ingots stirred at $1500 \mathrm{~W}$, the DAS is large because the continuous homogenization of the liquid and removal of small arms that grow freely and almost spheroidally in the liquid allowed dendrites to grow; in this case, the increase in DAS is only limited by the growth of another dendrite or grain in the surrounding area, leading to a refined grain structure (GS for this condition was discussed above). For the ingots stirred at $3000 \mathrm{~W}$, the DAS is the largest for all three conditions with PC but decreased with PSC. This result can be explained by the same mechanism that resulted in ingots cast under this condition (3000 W, PC) having coarse grains: (1) the extensive stirring made possible by the higher power avoided the necking mechanism responsible for fragmentation, leading to further growth of existing arms, and (2) the physical contact between neighbouring dendritic arms led to their coalescing instead of fragmenting. However, when SC was used the additional cooling suppressed the spheroidization phenomenon, and as the stirring was less effective, the alloy solidified more dendritically.

The three graphs in Figure 11 show the average values of the microstructural parameters GS (a), DAS (b) and GS/DAS (c) for ingots cast by route 4 (Appendix B) with PC (black) and PSC (red) and stirred at 0,1500 and $3000 \mathrm{~W}$. The values in the graphs correspond to the average and overall standard deviation of the values for the distal, medial and proximal regions in Table 2. Without EMS, grains grew freely and only the type of cooling had a significant impact on grain growth, suggesting that the addition of an extra cooling system ensured more effective grain refinement. EMS at 1500 $\mathrm{W}$ resulted in greater grain refinement than EMS at 3000 $\mathrm{W}$, indicating that higher power values are not synonymous with optimal stirring. For the combined cooling systems, the DAS (Figure 11b) for the 0 and $3000 \mathrm{~W}$ conditions was 


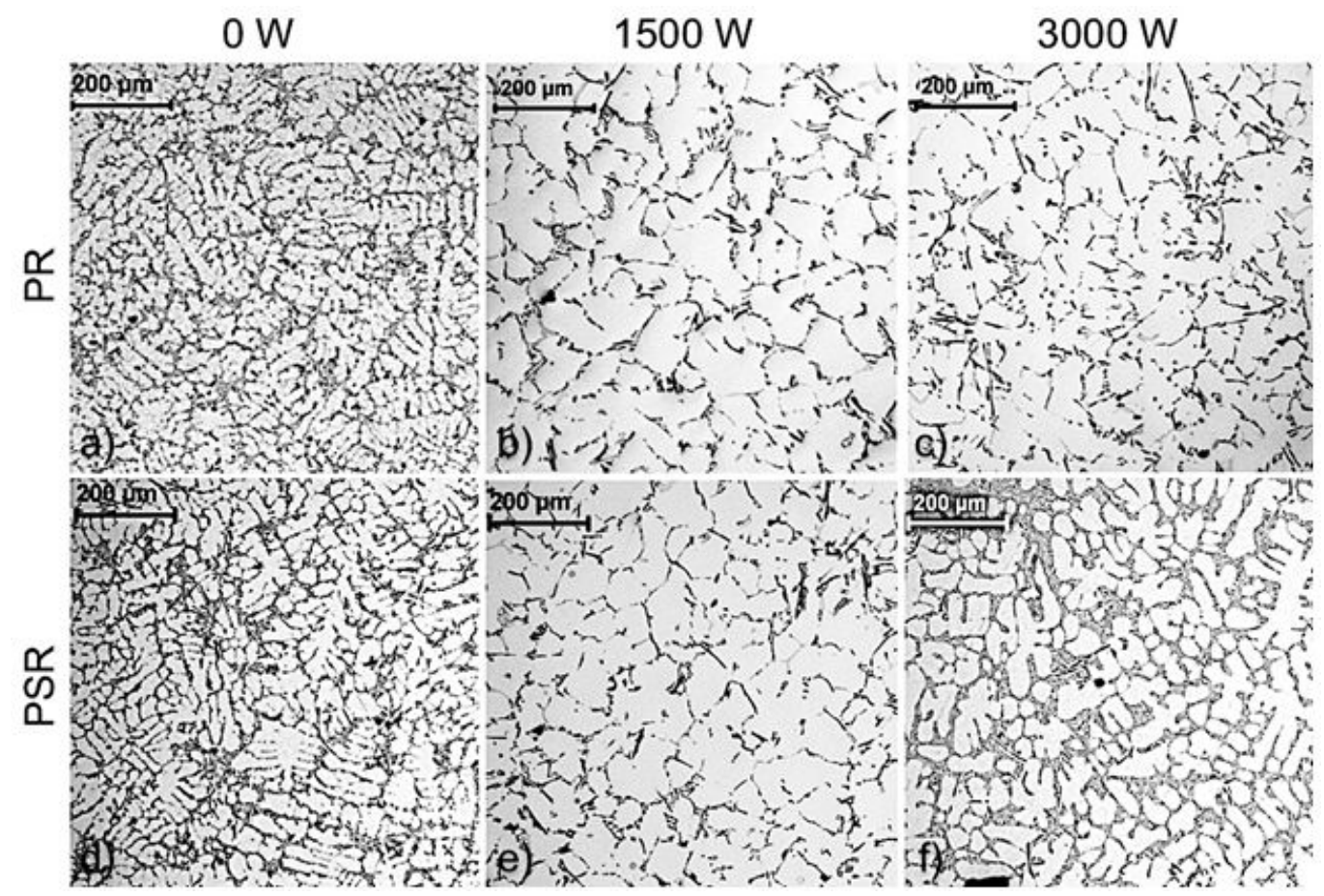

Figure 10. BF microstructure of the medial region of an ingot cast by route 4 with PC (top) and PSC (bottom) and without EMS (a, d) and with EMS (1500: b, e; $3000 \mathrm{~W}: \mathrm{c}, \mathrm{f})$.

practically the same as for a single cooling system. However, for $1500 \mathrm{~W}$ this parameter increased significantly, indicating that the combination of secondary cooling and intermediate EMS $(1500 \mathrm{~W})$ produced smaller grains with fewer dendrites, i.e., the DAS approached the GS under these conditions. This result is clearly visible in Figure 10b, e, unlike in the other micrographs in the same figure.

The ratio GS/DAS (Figure 11c) is considerably larger for ingots that were not stirred for both PC (GS/DAS 10) and PSC (GS/DAS 6). The absence of stirring allowed grain growth to take place in the direction in which heat was extracted, producing large grains with long, fine dendrites and, consequently, the largest GS/DAS ratio amongst all the tested conditions. For the ingots stirred at $3000 \mathrm{~W}$, the limited necking and enhanced coalescence of dendritic arms combined with extensive grain growth resulted in DAS values that were still large $(\sim 7)$ when only PC was used. Secondary cooling at the mould exit prevented the final stage of grain growth but did not affect the mechanisms induced by stirring at $3000 \mathrm{~W}$ (growth of dendritic arms), resulting in a reduction of the GS/DAS ratio to approximately 3 . Finally, stirring at $1500 \mathrm{~W}$ resulted in the smallest GS/DAS ratios: approximately 3.5 for $\mathrm{PC}$, which produced refined but still dendritic grains, and close to 1 for PSC, which produced not only refined but also less dendritic grains, which are ideal for thixoforming processes.

The similarity of the results for the proximal, medial and distal regions for each of the conditions analysed ensures good repeatability and control of the process, indicating that the continuous casting device presented here is sufficiently robust to be easily adapted by small companies.
For subsequent SSM processing, the refined, equiaxed grain structure associated with a ratio of GS/DAS $\rightarrow 1$ observed for the ingot stirred at $1500 \mathrm{~W}$ and cooled with the combined cooling system makes this condition the most suitable for thixoforming as this grain structure will spheroidize more successfully when the feedstock is partially melted, resulting in a thixotropic rheology during forming.

\section{Conclusions}

The development of a continuous casting system that would provide an efficient route for producing Al-Si alloys with a refined microstructure for use as SSM feedstock resulted in the following conclusions: a) ingots produced with combined (primary and secondary) cooling had the best microstructural homogeneity in all the directions analyzed; b) optimal EMS was achieved with a power level of $1500 \mathrm{~W}$ $\left(\mathrm{EMF}_{\max }=22 \mathrm{G}\right)$, which resulted in the most effective grain refinement of all the conditions tested. This result suggests that the existence of a relationship between the mass of the molten metal and the EMF and that there is a power level corresponding to maximum power efficiency (minimum power with maximum grain refinement). By using the parameter values corresponding to this point of maximum efficiency, a reduction in grain size of $96 \%$ was achieved (from an average of $3 \mathrm{~mm}$ to an average of $178 \mu \mathrm{m}$ ). This degree of refinement is acceptable for SSM feedstock as further grain refinement and spheroidization is achieved during partial melting treatment prior to thixoforming. 


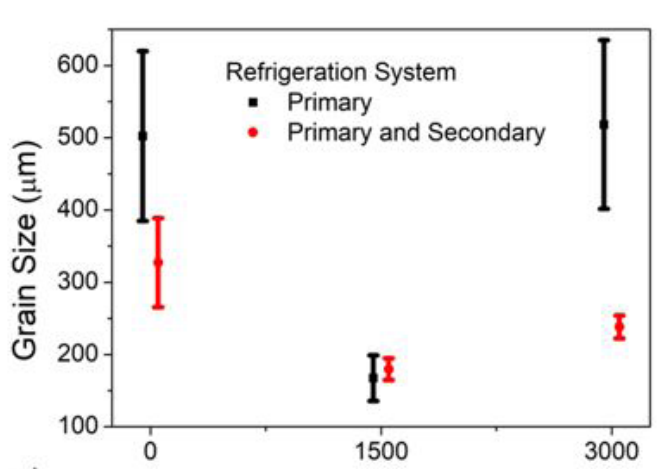

a)

Electro Magnectic Power (W)

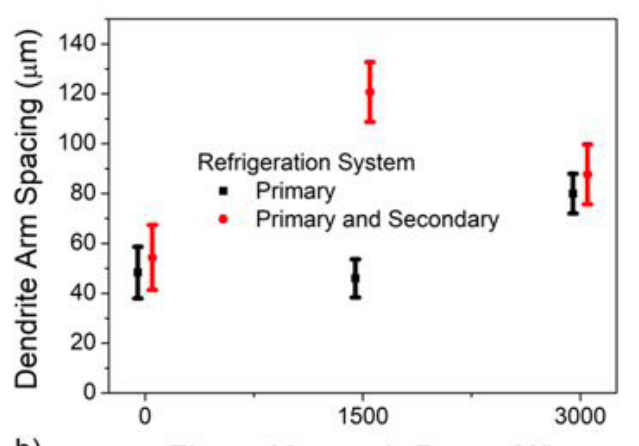

b) Electro Magnectic Power (W)

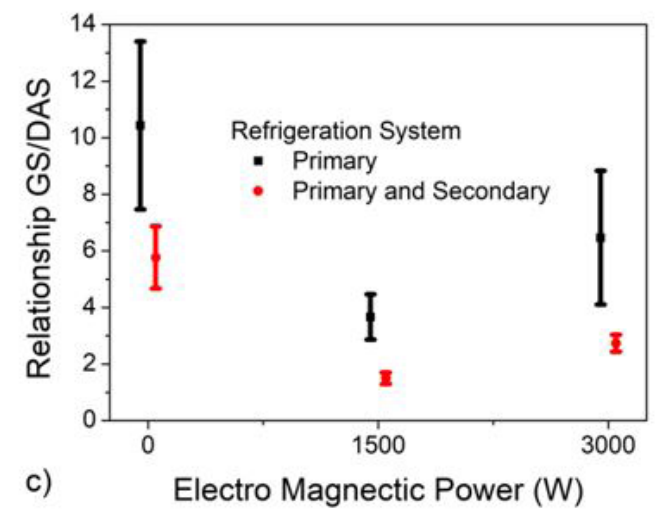

Figure 11. Interval between minimum and maximum values of the microstructural parameters GS (a), DAS (b) and GS/DAS (c) for ingots cast by route 4 with PC (black) and PSC (red) and stirred at 0,1500 and $3000 \mathrm{~W}$. The values in the graphs correspond to the average and overall standard deviation of the values for the distal, medial and proximal regions in Table 2.

\section{Acknowledgments}

The authors would like to thank the Brazilian research funding agencies FAPESP (São Paulo Research Foundation Projects 2013/09961-3 and 2015/22143-3), CNPq (National Council for Scientific and Technological Development—Project CNPq PQ 304921-2017-3), and CAPES (Federal Agency for the Support and Improvement of Higher Education) for providing financial support for this study. The authors are also indebted to the Faculty of Mechanical Engineering at the University of Campinas and to the Federal Institute of Education, Science and Technology of São Paulo Itaquaquecetuba campus (IFSP) for the practical support very kindly provided.

\section{References}

1. Zoqui EJ. Alloys for semisolid processing. In Hashmi S. editor. Comprehensive materials processing. USA: Elsevier; 2014. p. 163-190.

2. Li M, Li Y, Zhou H. Effects of pouring temperature on microstructure and mechanical properties of the A356 aluminum alloy diecastings. Mater Res. 2020;23(1):e20190676.

3. Atkinson HV. Modelling semi-solid processing of metallic alloys. Prog Mater Sci. 2005;50:341-412.

4. Kirkwood DH, Suéry M, Kapranos P, Atkinson HV, Young KP. Semisolid processing of alloys. Berlin: Springer-Verlag Berlin Heidelberg, 2010.

5. Flemings MC. Behaviour of metal alloys in the semi-solid state. Metall Trans, A, Phys Metall Mater Sci. 1991;22A:957-81.

6. Samata S, Omara MZ, Mohameda IF. High-frequency induction heating of Al-Si-Cu-Mg aluminum alloy in thixoforming. Mater Res. 2019;22(5):e20190253.

7. Freitas ER, Ferracini EG Jr, Piffer P, Ferrante M. Microestructure, material flow and tensile properties of A356 alloy thixoformed parts. Mater Res. 2004;7(4):595-603.

8. Chiarmetta G. Why thixo? In Proceedings of the 6th International Conference on Semisolid Processing of Alloys and Composites; 2000 Sept 27-29; Turin, Italy. Turin: Edimet; 2000. p. 15-21.

9. Padmanaban S, Subramanian R, Anburaj J, Thillairajan K. Rheo-die-casting of Al-Si-Mg alloy and Al-Si-Mg/ SiCp composites: microstructure and wear behavior. Mater Res. 2020;23(2):e20200063.

10. Chen Y, Wei J, Zhao Y, Zheng J. Microstructure evolution and grain growth behavior of Ti14 alloy during semi-solid isothermal process. Trans Nonferrous Met Soc China. 2011;21(5):1018-22.

11. Reisi M, Niroumand B. Growth of primary particles during secondary cooling of a rheocast alloy. J Alloys Compd. 2009;475(1-2):643-7.

12. Lashkari O, Ghomashchi R. The implication of rheology in semi-solid metal processes: an overview. J Mater Process Technol. 2007;182(1-3):229-40.

13. Perez M, Barbé JC, Neda Z, Bréchet Y, Salvo L. Computer simulation of the microstructure and rheology of semi-solid alloys under shear. Acta Mater. 2000;48(14):3773-82.

14. Bustos O, Ordoñez S, Colás R. Rheological and microstructural study of A356 alloy solidified under magnetic stirring. Int J Met Cast. 2015;15(1):144-50.

15. Chen X, Zhang Z, Xu J. Effects of annular electromagnetic stirring processing parameters on semi-solid slurry production. Trans Nonferrous Met Soc China. 2010;20(3):873-7.

16. Nafisi S, Emadi D, Shehata MT, Ghomashchi R. Effects of electromagnetic stirring and superheat on the microstructural characteristics of Al-Si-Fe alloy. Mater Sci Eng A. 2006;432(12):71-83.

17. Tang M, Xu J, Zhang Z, Bai Y. New method of direct chill casting of Al-6Si-3Cu-Mg semisolid billet by annulus electromagnetic stirring. Trans Nonferrous Met Soc China. 2010;20(9):1591-6.

18. Chen Y, Zhang L, Liu W, Wu G, Ding W. Preparation of $\mathrm{Mg}-\mathrm{Nd}-\mathrm{Zn}-(\mathrm{Zr})$ alloys semisolid slurry by electromagnetic stirring. Mater Des. 2016;95:398-409.

19. Ordoñez S, Bustos O, Colás R. Thermal and microstructural analysis of an A356 aluminium alloy solidified under the effect of magnetic stirring. Int J Met Cast. 2009;3:37-41.

20. Zhu G, Xu J, Zhang Z, Bai Y, Shi L. Annular electromagnetic stirring: a new method for the production of semi-solid A357 
aluminum alloy slurry. Acta Metall Engl Lett. 2009;22(6):40814.

21. Zoqui EJ, Gracciolli JI, Lourençato LA. Thixo-formability of the AA6063 alloy: conventional production processes versus electromagnetic stirring. J Mater Process Technol. 2008;198(13):155-61.

22. Proni CTW, Torres LV, Haghayeghi R, Zoqui EJ. ECAP: an alternative route for producing AlSiCu for use in SSM processing. Mater Charact. 2016;118:252-62.

23. Paes M, Zoqui EJ. Semi-solid behavior of new Al-Si-Mg alloys for thixoforming. Mater Sci Eng A. 2005;406(1-2):63-73.

24. Nadal RL, Roca AS, Fals HDC, Zoqui EJ. Mechanical properties of thixoformed hypoeutectic gray cast iron. J Mater Process Technol. 2015;226:146-56.

25. Haghayeghi R, Zoqui EJ, Timelli G. Enhanced refinement and modification via self-inoculation of Si phase in a hypereutectic aluminium alloy. J Mater Process Technol. 2018;252:294-303.

26. Roca AS, Fals HDC, Pedron JA, Zoqui EJ. Thixoformability of hypoeutectic gray cast iron. J Mater Process Technol. 2012;212(6):1225-35.

27. Campo KN, Zoqui EJ. Thixoforming of an ECAPed aluminum A356 alloy: microstructure evolution, rheological behavior, and mechanical properties. Metall Mater Trans, A Phys Metall Mater Sci. 2016;47:1792-802.

28. Proni CTW, Brollo GL, Zoqui EJ. A comparison of the use of ultrasonic melt treatment and mechanical vibration in the manufacture of A15Si5Zn alloy feedstock for thixoforming. Metall Mater Trans, B, Process Metall Mater Proc Sci. 2020;51:306-17.

29. Haghayeghi R, Paula LC, Zoqui EJ. Comparison of Si refinement efficiency of electromagnetic stirring and ultrasonic treatment for a hypereutectic Al-Si alloy. J Mater Eng Perform. 2017;26:1900-7.

30. Kapranos, P. Current state of semi-solid net-shape die casting. Metals. 2019;9(12):1301. https://doi.org/10.3390/met9121301.

31. ASTM International. B179-18 - Standard Specification for Aluminum Alloys in Ingot and Molten Forms for Castings from All Casting Processes. West Conshohocken, PA; ASTM International; 2018. https://doi.org/10.1520/B0179-18.

32. ASTM International. ASM Metals Handbook. 10th ed. Vol. 2. West Conshohocken, PA; ASTM International; 1990.
33. ASTM International. E112-13 standard test methods for determining average grain size. West Conshohocken, PA; ASTM International; 2013. https://doi.org/10.1520/E0112-13.

34. Kazakov AA, Luong NH. Characterization of semisolid materials structure. Mater Charact. 2001;46(2-3):155-61.

35. Zoqui EJ, Shehata MT, Paes M, Kao V, Es-Sadiqi E. Morphological evolution of SSM A356 during partial remelting. Mater Sci Eng A. 2002;325(1-2):38-53.

36. Sigworth G. Understanding quality in aluminum castings. Int J Met Cast. 2011;5:7-11.

37. Campbell J. Stop pouring, start casting. Int J Met Cast. 2012;6:718.

38. Fiorese E, Bonollo F, Timelli G, Arnberg L, Gariboldi E. New classification of defects and imperfections for aluminum alloy castings. Int J Met Cast. 2015;9:55-66.

39. Yang Y, Liu X, Wang S. Thermal characteristics of induction heating with stepped diameter mold during two-phase zone continuous casting high-strength aluminum alloys. Int J Heat Mass Transfer. 2020;152:119479.

40. Mahallawi E, Eldeen IS, Mahmoudb TS, Gaaferb AM, Mahmoudb FH. Effect of pouring temperature and water cooling on the thixotropic semi-solid microstructure of a319 aluminium cast alloy. Mater Res. 2015;18(1):170-6.

41. Pinto P, Peixinho N, Soares D, Silva F. Process development for manufacturing of cellular structures with controlled geometry and properties. Mater Res. 2015;18(2):274-82.

42. Farina ME, Bell P, Ferreira CRF, Dedavid BA. Effects of solidification rate in the microstructure of $\mathrm{Al}-\mathrm{Si} 5 \mathrm{Cu} 3$ aluminum cast alloy. Mater Res. 2017;20(2):273-8

43. Baptista LAS, Ferreira AF, Paradela KG, Silva DM, Castro JA. Experimental investigation of ternary Al-Si-Cu alloy solidified with unsteady-state heat flow conditions. Mater Res. 2018;21(3):e20170565.

44. Garcia A. Solidificação: fundamentos e aplicações. Campinas: Unicamp; 2008.

45. Suarez MA, Figueroa I, Cruz A, Hernandez A, Chavez JF. Study of the Al-Si-X system by different cooling rates and heat treatment. Mater Res. 2012;15(5):763-9.

46. Ayabe M, Nagaoka T, Shibata K, Nozute H, Koyama H, Ozaki $\mathrm{K}$, et al. Effect of high thermal conductivity die steel in aluminum casting. Int J Met Cast. 2008;2:47-55. 


\section{Supplementary material}

The following online material is available for this article:

Appendix A - Design and construction of the continuous casting device.

Appendix B - Choice of processing and construction parameters. 